\title{
An instrument for semi-continuous monitoring of the size-distribution of nitrate, ammonium, sulphate and chloride in aerosol
}

\author{
H.M. ten Brink \\ R.P. Otjes \\ P.A.C. Jongejan \\ S. Slanina
}

Published in Atmospheric Environment 41 (2007) 2768 - 2779 


\title{
An instrument for semi-continuous monitoring of the size-distribution of nitrate, ammonium, sulphate and chloride in aerosol
}

\author{
Harry ten Brink*, René Otjes, Piet Jongejan, Sjaak Slanina ${ }^{1}$ \\ Energy Research Centre of the Netherlands (ECN), Westerduinweg 3, Building 04, 1755 ZG Petten, The Netherlands
}

Received 15 May 2006; received in revised form 10 November 2006; accepted 21 November 2006

\begin{abstract}
An instrument was developed for semi-continuous measurement of the size-distribution of submicron nitrate, ammonium, sulphate and chloride. Novel in the instrumentation is the size-classification, which is realised with a preseparator that consists of a set of four parallel impactors. The cut-off diameters of the impactors are at $0.18,0.32,0.56$ and $1.0 \mu \mathrm{m}$. Aerosols smaller than the associated cut-off size pass the respective impactor and arrive in the detector. The manifold with impactors contains two additional lines, one open line and one containing a filter that removes all aerosols. This latter line provides an on-line field-blank. The sample air-flow is automatically switched by wide-bore ball valves to one of the six sampling lines for a period of $20 \mathrm{~min}$; a measuring cycle thus takes $2 \mathrm{~h}$.

Down-stream of the pre-separator the sampling and automated on-line analysis of the transmitted aerosol is accomplished with a "MARGA". In this instrument steam condensation is used to grow the aerosol. The droplets formed are collected in a cyclone that drains to wet-chemical analysis systems. A wet-denuder between pre-separator and collector removes interfering gases, like nitric acid and ammonia. This enables artefact-free and thus representative semi-continuous measurement of the size-distribution of the semi-volatile (ammonium) nitrate.

The novel MARGA-sizer was first used in a 1 week field-test. After modifications it was then deployed in a monitoring campaign of 2 months in the summer of 2002, at the top level of the meteo-tower of Cabauw in the centre of the Netherlands. The high location, $200 \mathrm{~m}$, was chosen to obtain data on ammonium nitrate that are minimally affected by surface emissions of ammonia. The data coverage over the period was over $60 \%$; failure of the instrumentation was mainly associated with spells of extreme solar heating of the tower and associated high temperatures inside.

The average concentration of nitrate was $2.6 \mu \mathrm{g} \mathrm{m}^{-3}$, which was very similar to the value interpolated from data in the national network. The mass concentration of submicron nitrate was $2.0 \mu \mathrm{g} \mathrm{m}^{-3}$, of which $46 \%$ was in particles smaller than $0.32 \mu \mathrm{m}$. To put this in perspective: the concentration of submicron sulphate was similar to that of nitrate, while $53 \%$ was in particles smaller than $0.32 \mu \mathrm{m}$. The ion balance showed that the compounds were present as the fully neutralised salts. Quite large diurnal variations were observed for nitrate, with a surprising maximum in the afternoon. The size-distribution of the semi-volatile nitrate was rather constant over a daily cycle.

(C) 2006 Elsevier Ltd. All rights reserved.
\end{abstract}

Keywords: Nitrate; Ammonium; Sulphate; Light-scattering

\footnotetext{
${ }^{*}$ Corresponding author. Fax: +31224568488.

E-mail address: tenbrink@ecn.nl (H. ten Brink).

${ }^{1}$ Present address: Peking University.
} 


\section{Introduction}

Very little information exists on the size-distribution of aerosol components, while such knowledge is essential for a proper assessment of their atmospheric processing and the effects they exert. In this respect the precise knowledge of the size-distribution is critical in assessing the amount of light scattered by an atmospheric aerosol (Seinfeld and Pandis, 1998).

The strong sensitivity with respect to size of the light-scattering by a compound is best appreciated when the mass distribution is considered. The maximum scattering occurs when the mass is concentrated in particles with a diameter that is comparable in size with the wavelength of the radiation (Nemesure et al., 1995). When the same mass is contained in particles that are three times larger or smaller, the light-scattering is an order of magnitude less.

Scattering of solar radiation by, manmade, aerosol constituents leads to significant cooling of climate via the aerosol radiative forcing effect (Penner et al., 2001). It is common belief that sulphate is the dominant light-scattering component of the aerosol. While concentrations of aerosol nitrate are quite significant, the component was not considered important for aerosol forcing, because it would be primarily present in coarse particles that are not effective in scattering light (Jacobson, 2001). On the other hand, Adams et al. (2001) estimated that the contribution of nitrate to the aerosol forcing is large, when it is assumed that the size-distribution of nitrate is similar to that of sulphate, which is mostly in the submicron aerosol.

Support for the assumption that nitrate is in small particles comes from data in Europe showing that nitrate it is a dominant species of the aerosols smaller than $2.5 \mu \mathrm{m}$ in diameter (Putaud et al., 2004). However, only in case it would be concentrated in submicron particles and more specifically in particles of around $0.5 \mu \mathrm{m}$ in diameter, it would be as effective as sulphate, which is considered to be the dominant component in the aerosol radiative forcing effect in our region.

The foregoing shows that detailed information on the distribution, as a function of size, is required for a quantification of the role of nitrate in the direct aerosol radiative effect. There are data showing that its contribution is large in our region (e.g., ten Brink et al., 1996, 1997). There are two caveats: the number of data is limited and the data have a severe bias in the summer due to sampling artefacts for ammonium nitrate.

The issue of the high sensitivity of optical properties towards size also applies for the satellite-retrieval of aerosols, in which use is made of the solar radiation scattered by the aerosols. The contribution of an aerosol compound to the signal depends on its size-distribution (Robles Gonzalez et al., 2003, and references therein). In the analysis of the signals a fixed size-distribution is used, which is most likely not representative. The reason is that the distribution is based on $24 \mathrm{~h}$ integrated values, while the relevant scattering of solar radiation occurs during the, short, time of overpass of a satellite. Therefore data are needed for that specific time, which requires measurements with a high time-resolution.

There is a special reason for interest in data on nitrate and sulphate, because the compounds are hygroscopic and thus attract water. The amount of water they attract is so large that the compounds become the dominant light-scatterers in our region (Dougle et al., 1998; ten Brink et al., 1996). The enhanced scattering due to the water uptake depends on RH and the concentrations of the two components and should be accounted for in satellite retrieval (Veefkind, 1999).

There is another reason for gathering new data, specifically on nitrate, because the quality of the existing data for nitrate is not assured. This typically applies for the season in which the optical effects are most pronounced, because of the long duration of the sunshine, viz., the summer season. The concern on the quality of the data stems from the semivolatile character of the nitrate compound in question, ammonium nitrate. This constituent is liable to evaporation during collection.

Volatilisation of ammonium nitrate is a function of temperature and should therefore especially occur in summer. Indeed, such volatilisation was clearly demonstrated in a study in the Netherlands, in which the concentration of nitrate obtained with cascade-impactors was compared with that gathered via representative filter-sampling (Chang et al., 2001). It was seen that the impactor collected much less nitrate, while for the conservative sulphate the collected amount was similar via the two collection methods. The investigation took place in the summer season and the results confirmed evaporative losses seen in an earlier and less extensive study of ten Brink et al. (1997). 
The problems with the sampling-artefacts could in principle be overcome with methods in use for representative filter-collection of ammonium nitrate (Schaap et al., 2004), in which interfering nitric acid gas is removed and the substrates are prepared to retain the nitrate. However, this would require very costly preparation of all substrates in case of a cascade impactor as well as long-term testing of the performance of such a system. Also, all manual handlings involved are a likely source for contamination.

Obtaining data with a high time-resolution might also be useful in another respect. The detailed data could be helpful in improving models describing the atmospheric cycle of nitrate (Finlayson-Pitts and Pitts, 2000). A diurnal difference is expected that is associated with the secondary nature of the compound, which means that it is formed in the atmosphere. The formation processes depend on parameters like temperature, humidity and photochemical conditions, which have an obvious diurnal cycle.

In summary, there was a need for development of an automated system, as the one described below, for representative measurement of the size-distribution of ammonium nitrate over long periods of time. While in the foregoing emphasis was given to representative sampling of the semi-volatile ammonium nitrate, it was implicitly indicated that also the size-dependent concentration of the other major anionic component of submicron aerosol, viz., sulphate can be measured. Also chloride is determined.

There is an instrument (Fine et al., 2003; Stolzenburg et al., 2003) with which the sizedistribution of nitrate can be monitored. The aerosol collected in the impactors is analysed, which makes the method complimentary to the one we present here for nitrate; in our monitor the aerosol that passes the impactors is measured, including the nitrate in the smallest particles. Moreover, with in our method all major submicron ionic species are measured, also ammonium, which allows assessment of the fraction of nitrate that is present as the semi-volatile ammonium nitrate.

\section{Experimental}

\subsection{Design}

The new instrumentation is based on the MARGA (instrument for Measuring AeRosol and
GAses). The MARGA is an extension of the SJAC for collection of aerosol by condensing steam (Slanina et al., 2001). The aerosol is thus captured in water, which enables on-line analysis with wetchemical instrumentation.

An essential part of the MARGA is the denuder that removes gases, like nitric acid and ammonia, that would other wise be collected in the steam sampler and counted as aerosol component. The denuder also allows measurement of the gases and the MARGA hence derives its name from the possibility to measure aerosol and gas components simultaneously. Details on the MARGA are given elsewhere (Trebs et al., 2004).

\subsubsection{Pre-separator}

In the novel MARGA-sizer the central feature is the size-classification of the aerosol before collection. The size-classified sampling is accomplished with a pre-separator consisting of a set of four impactors. The impactors derive from commercial cascade-impactors. However, the individual impactors are placed in parallel and not in series as is the case in the standard cascade-setting. The working of the impactors is also different here, because the transferred aerosol is measured and not the aerosol collected on the impactor plates.

The pre-separator set-up is sketched in Fig. 1. For simplicity only four of the sampling lines are shown. The actual pre-separator consists of six parallel lines: there are four lines with an impactor and a line with a filter that removes all aerosol. This last line serves as the field-blank. The value obtained in this channel is subtracted from those in the other lines. The resulting corrected data are the concentrations of the components in particles smaller than the cutoff size of the respective impactor in the manifold. There is also a line without impactor or filter. The cut-off is not defined, but it is estimated that particles up to $10 \mu \mathrm{m}$ are effectively sampled.

Summarising, the pre-separator manifold consists of six lines of which four contain an impactor.

The impactors derive from a commercial micro orifice impactor (MOI). The advantage of this type of impactor is that it has a very modest pressure drop (of less than 5\%), even over the impactor with the lowest cut-off used. This approach was chosen after an unsuccessful earlier attempt to use stages from a low pressure impactor (Mikuska et al., 2001).

The impactors in the present pre-separator are those with the following nominal cut-off diameter, 


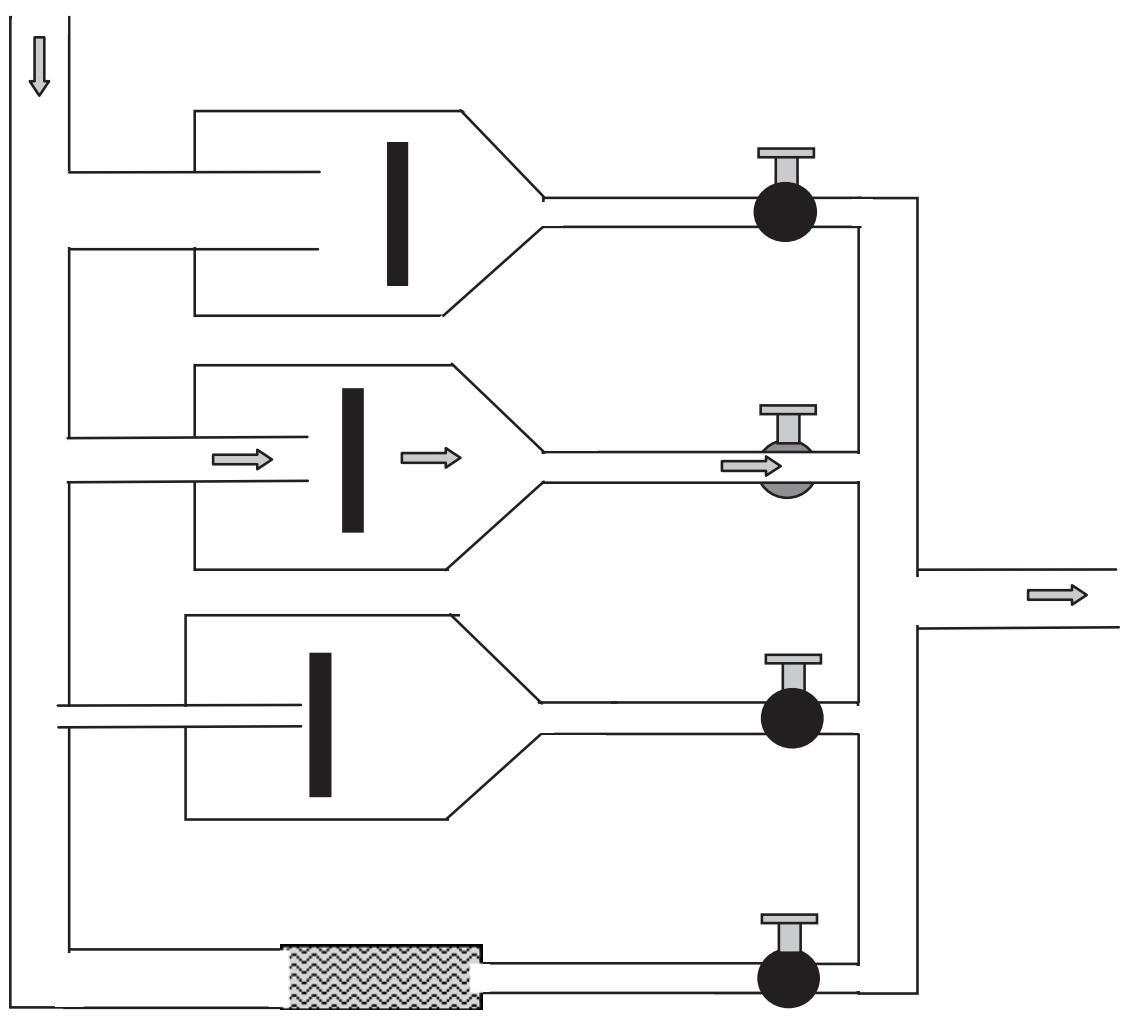

Fig. 1. Sketch of the pre-separator, consisting of a number of parallel lines with impactors. In the configuration shown the sample air is drawn in from above left through the second line, with the open valve, to the detector. Via this line aerosol is transmitted that is smaller than the cut-off diameter of the impactor. For simplicity only four lines of the manifold are shown. The actual MARGA-sizer instrument contains a pre-separator with six parallel lines, of which four with impactors, of $0.18,032,0.56$ and $1.0 \mu \mathrm{m}$ cut-off diameter. There is an additional "blank"-line, also shown in the sketch, containing a filter. Via a sixth open line total aerosol is sampled. In a measuring cycle the air-flow is successively drawn through one of the lines by the automated valves.

as given in the manual of the MOI (Marple et al., 1991):

$$
\begin{aligned}
& 1.0 \mu \mathrm{m}, \\
& 0.56 \mu \mathrm{m}, \\
& 0.32 \mu \mathrm{m}, \\
& 0.18 \mu \mathrm{m}
\end{aligned}
$$

In order to protect the stages from clogging by coarse particles, each impactor is preceded by a preimpactor with a larger cut-off diameter. The construction of the manifold, sketched in Fig. 1, was made in-house. It was checked whether the characteristics of the impactors used as stand-alone units were similar to those in a cascade-impactor. According to theory there should be a minimal difference because of the very limited pressure drop.

The impactor with a cut-off of $0.32 \mu \mathrm{m}$ was checked with respect to its cut-off, because it was initially the stage with the lowest cut-off. It was expected from theory that the cut-off diameter would differ by less than $1 \%$ from that in the cascade-setting, because of the small pressure drop. Tests were performed to confirm this. Monodisperse polystyrene latex was used and the transmission was determined with an optical counter (LAS-X). The $50 \%$ cut-off was at $0.33( \pm 0.01) \mu \mathrm{m}$. This is in accordance with the predicted minimal shift.

In a test of a week in the field, it became clear that the components could be present in smaller aerosols than initially anticipated from measurements in the past. Hence an impactor with a lower cut-off diameter of $0.18 \mu \mathrm{m}$ was added for the actual measuring campaign described below. The performance of this impactor was not checked. It should be considered, however, that the pressure drop over the impactor is small, less than $50 \mathrm{mbar}(50 \mathrm{~Pa})$. This implies that the cut-off characteristics should only be slightly different from that in the cascade setting. In the cascade the back pressure is lower than in the 
stand-alone version, due to pressure drop over all of the preceding stages in the cascade. Theory says that the cut-off in the stand-alone version could thus differ by $3 \%$ from that in the cascade. This shifts the cut-off diameter from 0.18 to $0.185 \mu \mathrm{m}$. Because of the small difference and an experimental uncertainty in characterising the actual cut-off, we use the nominal value of $0.18 \mu \mathrm{m}$ here.

For automated operation of the pre-separator the sample-flow is cycled via wide-bore valves (type EA, End-Armaturen $\mathrm{GmbH}$, Bad Oeynhausen, Germany; bore size $\frac{1}{2}$ in) to one of the sampling lines, see Fig. 1, for a sketch. The transmission of aerosol through the valves was checked and we did not observe a measurable loss of aerosol. An in-house provision was made for automatic switching of the valves, in such a way that successively a sampling line is opened and the others closed. Each line samples for a period of $20 \mathrm{~min}$. A measuring cycle thus takes $2 \mathrm{~h}$.

The proper long-term performance of the cycling of the airflow in the pre-separator was checked at the institute drawing air from outside. Ammonium was used as reference compound in this test, because its detection was the most advanced at the time. The test consisted of confirming that less material was transmitted in lines with consecutively lower cut-off diameter. In the field test and subsequent campaign proper switching was deduced from the pressure drop over the specific impactors.

The size-classified measurements require a good resolution in the analysis system, in the sense that analyte deriving from consecutive sampling steps should be well separated. This means, in analytical terms, that carry-over of aqueous samples should be negligible or at least small compared to the actual values. This was indeed the case, as will be shown in the evaluation of the results below.

As for the mass concentration of the components in a size class, this is not directly measured because we determine the concentration of components in the aerosol particles smaller than the cut-off diameters of the respective impactors. However, the mass-distribution as a function of size can be easily derived from the difference in concentration of the aerosol passing two consecutive impactors. More details on the evaluation are provided in the section on the results.

\subsubsection{Gas-denuder}

Essential, in the context of the collection of the semi-volatile ammonium nitrate, is the removal of gases that interfere in the analysis of the aerosol components. These gaseous compounds, ammonia and nitric acid, are water-soluble and are efficiently sampled in the steam collector and counted as the respective aerosol constituent. To prevent the gases from entering the aerosol collector a gas-denuder is used. The denuder is between the pre-separator manifold and aerosol-collector. The reason that the denuder is not at the entrance is that it works as a humidifier, which would lead to undesired growth of the particles.

The denuder also removes gases that may originate from ammonium nitrate collected by the impactors or filter over a longer period and evaporating later. This could especially occur in situations in which the ammonium nitrate is sampled at low temperatures; this might evaporate from the impactor plates under warmer conditions.

As mentioned above, ammonium nitrate is semivolatile and it might be questioned whether aerosol nitrate can evaporate during passage of the aerosol through the denuder or at the high temperatures occurring in the steam collector. Such evaporation is not significant for total ammonium nitrate (Slanina et al., 2001), but could be important for the smallest aerosols, which most easily volatilise. It can be argued that this is not even the case for the smallest particles, those with a diameter of $0.1 \mu \mathrm{m}$. We demonstrated that the characteristic time for evaporation of pure ammonium nitrate of this size is in the order of $10 \mathrm{~s}$ (Khlystov et al., 1997). Moreover, at the high $\mathrm{RH}$ in the wet-denuder, evaporation is much further suppressed. Summarising, the characteristic time for evaporation of $10 \mathrm{~s}$ is much longer than the transit time through the denuder, which is typically $0.15 \mathrm{~s}$ and volatilisation of ammonium nitrate in the denuder is thus negligible.

The denuder not only serves for removal of the gases, but it can be used to measure the concentration of the gases mentioned above. This is done via analysis of the contents of the water draining from the denuder. Because the new instrument measures both size-fractionated aerosol and gases, it is termed MARGA-sizer.

A last question concerns the behaviour of the semi-volatile ammonium nitrate in the steam collector. The introduction of the steam enhances the temperature and this could lead to volatilisation. However, the decomposition products are so soluble that they are also fully taken up in the water, as was experimentally verified. 


\subsection{Field monitoring}

A monitoring campaign with the newly developed instrumentation took place at the top level of the $200 \mathrm{~m}$ high meteo-tower of Cabauw, in the centre of the Netherlands. The instrumentation was placed inside the tower with a short sampling line extending outside.

A more elevated sampling location was required because the concentration of the semi-volatile ammonium nitrate is affected by the concentration of ammonia. This component can have a quite steep vertical gradient in the Netherlands due to local surface emissions (Allen et al., 1989). The concentration of ammonium nitrate depends on that of ammonia because of the equilibrium with the two precursor gases to which also nitric acid belongs. This gas is produced in the atmosphere and is therefore quite equally distributed throughout the planetary boundary layer. Variations in ammonia at the top of the tower are smaller and hence a more representative value for the regional ammonium nitrate concentration should be obtained.

The campaign was undertaken in the summer of 2002, lasting from June 21 to August 19. Servicing/ maintenance of the instrumentation was scheduled at a frequency of once a week. Data could be checked remotely at the institute and, in case of apparent malfunctioning, same-day or next-day repair could take place. The sampling-line, of copper with inner diameter of $10 \mathrm{~mm}$, was $2.5 \mathrm{~m}$ long, with the line extending for $1.5 \mathrm{~m}$ outside. It was shielded from direct solar irradiance.

Whereas outside temperatures were moderate, extra servicing was required due to the high temperatures inside the tower. This came quite unexpectedly, because the outside temperatures were moderate with maxima of less than $30^{\circ} \mathrm{C}$; however, temperature inside the tower could exceed $40^{\circ} \mathrm{C}$, which gave rise to malfunctioning of the electronics. A, possibly related issue was improper switching of the impactor-manifold. This was easily detectable via the registration of the pressure drop over the impactor stages. Data stemming from days with improper switching were disregarded.

The part of the copper sampling line that was inside the tower must have warmed up because of the higher temperatures inside. This implies that also the sampling air increased in temperature, which must have induced evaporation of the semivolatile ammonium nitrate. However, the transit time in the line is short and evaporation of ammonium nitrate should thus be minimal. Moreover, in case of some volatile loss the concentrations of ammonium nitrate as measured are minimum values, especially those in the smallest particles that most easily volatilise.

The high temperatures did affect the wet-denuder. Circulation of solution was often not at the optimum value required for analysis of the drain and sometimes the denuder dried out. It was feared that the drying would decrease the efficiency of the denuder; however, as demonstrated in the section on results below, this was not the case. The good performance for removal of nitric acid and hydrogen chloride did not come as a surprise, because the failure did not last longer than the time between two servicing days. For such a short period of time even plain glass tubing has sufficient capacity for removal and capture of nitric acid and hydrogen chloride (Thöni, private communication, January 2004).

\section{Results and discussion of the field monitoring campaign}

The MARGA-sizer was quite successfully operated at the top-level of the Cabauw meteo-tower, as shown in a data-coverage of $60 \%$. Complications associated with the high temperatures inside the tower, as discussed above, were the main reason for absence of more data. Because of the special interest in summer-time data for nitrate, we will start with the evaluation of the results for this compound, followed by that for the other compounds. Another reason for evaluation of the nitrate data is that it was straightforward.

\subsection{Nitrate}

The raw data show that the concentration of nitrate in a measuring cycle decreases going from sampling all aerosol to subsequently smaller aerosols and aerosol-free air in the line with the filter. In the evaluation first the blank values, meaning the concentrations obtained via the line with the aerosol-filter (Fig. 2), were analysed. A residual blank value can be observed, which is however small compared to the values of the submicron nitrate, as seen in Fig. 2. Further evaluation of the blank showed that it was not correlated with the value of nitrate in the preceding step in the sampling cycle. Such a correlation occurs when part of a sample is carried over to the next analysis step. In the section 

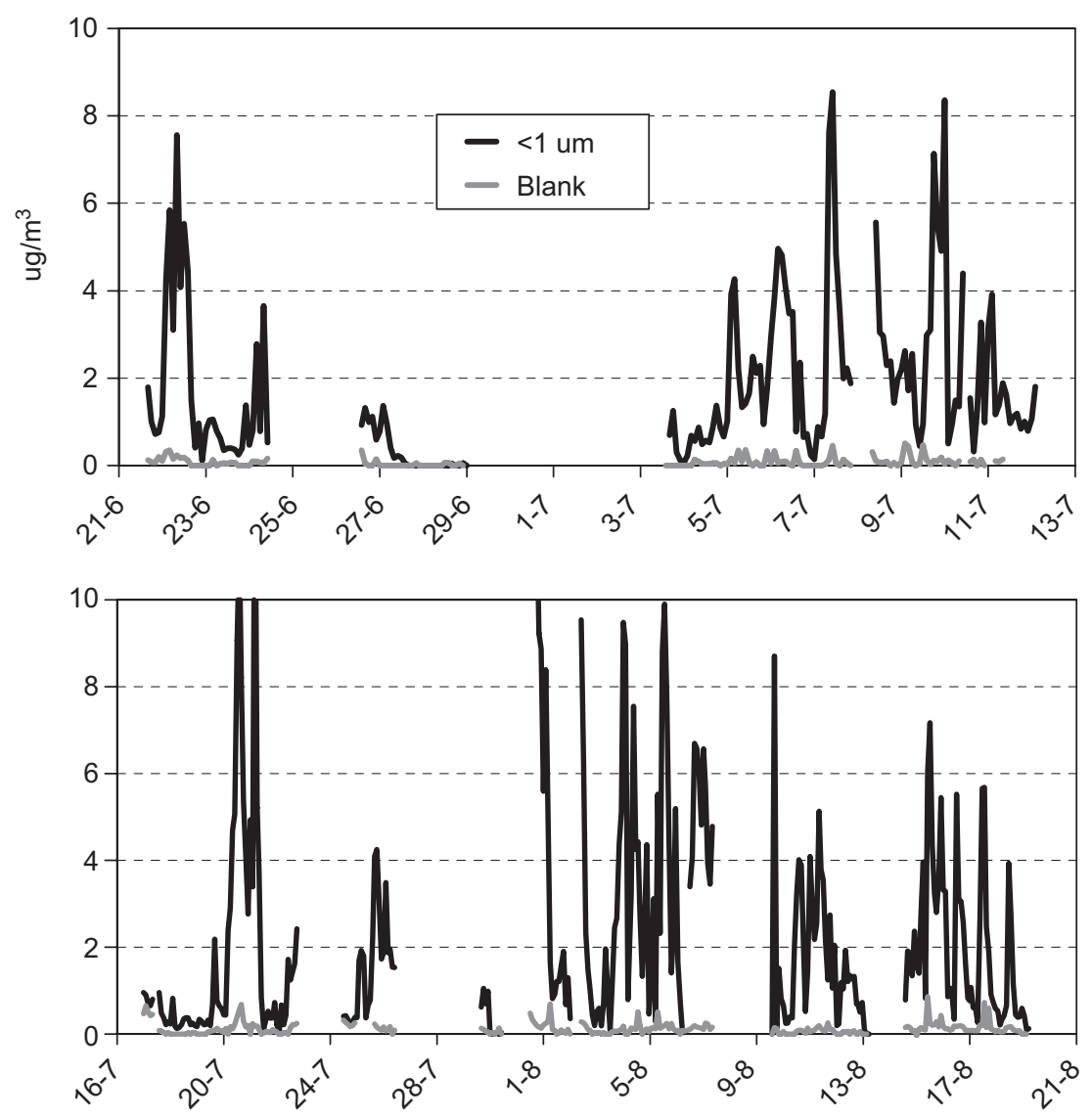

Fig. 2. Time series of the concentration of aerosol-nitrate in summer 2002, in the indicated period, at the top-level of the $200 \mathrm{~m}$ high meteo-tower of Cabauw in the centre of the Netherlands. Shown is the concentration of submicron nitrate and the value of the blank, i.e., the value measured in the line in which all aerosol is removed with a filter, see Fig. 1.

on sulphate below it is shown that this interference for sulphate was very small. Because nitrate has less hold-up in the analysis train than sulphate, the carry-over of sample from a previous step in the sampling and analysis cycle should indeed be negligible.

While the blank did have a bias during the campaign, there appeared to be some long-term drift in the analysis system, in the sense that the blank value differed between two zero-settings on servicing dates. This periodic difference has no implications for the data, because in the evaluation we subtract the actual blank as obtained per measuring cycle. The lower detection limit (LOD) depends on the variation in the blank and this was determined for the values as obtained in the period between two servicing days. The standard deviation (SD) in the variation in the blank was $0.06 \mu \mathrm{g} \mathrm{m}^{-3}$. This SD translates into a lower limit of detection (LOD) of $0.18 \mu \mathrm{g} \mathrm{m}^{-3}$.
The average concentration of nitrate, corrected for the blank, was $2.6 \mu \mathrm{g} \mathrm{m}^{-3}$, which is much higher than the LOD. The concentration of nitrate in the fraction of aerosol smaller than $1 \mu \mathrm{m}$ is $2.0 \mu \mathrm{g} \mathrm{m}^{-3}$, showing that the compound is preferentially present as submicron nitrate. An example of the distribution of the submicron nitrate in four submicron fractions is provided in Fig. 3. The way of depicting these results has been take from Stolzenburg et al. (2003) for similar results in California. Fig. 3 shows the detailed data for a period of 5 days in August. The figure is an illustration that, over the whole of the measuring campaign, almost half $(46 \%)$ of the submicron nitrate was in particles smaller than $0.32 \mu \mathrm{m}$. For those interested in the complete data set we refer to the CREATE data-base in which all results have been tabulated (www.nilu.no/projects/ $\mathrm{ccc} /$ create).

As for the distribution of nitrate in a size class, this can be quite easily visualised in a graph like that 


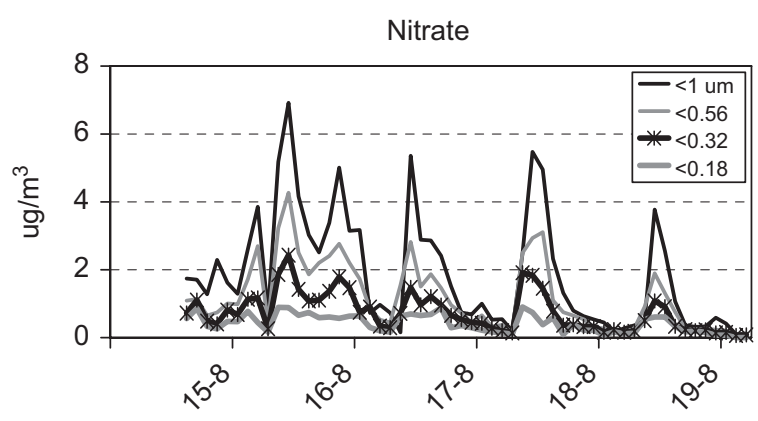

Sulphate

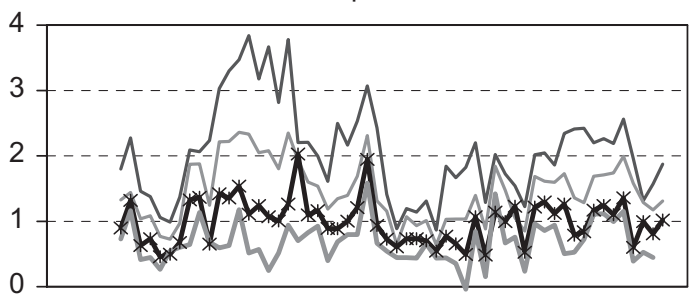

Ammonium

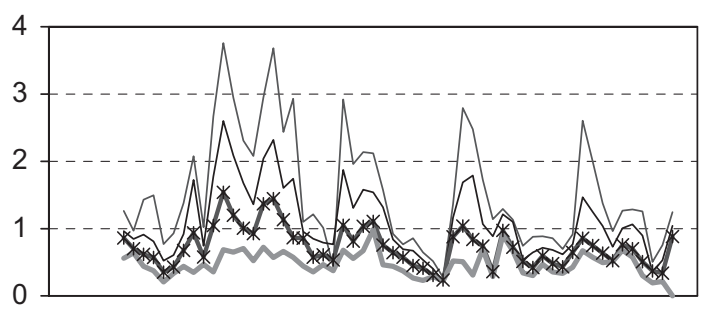

Fig. 3. Detail of the concentration of nitrate in particles smaller than the indicated diameter in the indicated week during the campaign described in Fig. 2. The concentrations are corrected for the blank. Sulphate and ammonium are also presented, but note the different vertical scales for the components.

in Fig. 3. The line closest to the $x$-axis shows the concentration of nitrate in the particles smaller than $0.18 \mu \mathrm{m}$. The next line presents the concentration in particles smaller than $0.32 \mu \mathrm{m}$. Hence the vertical distance between the two lower lines gives the concentration in the size class of $0.18-0.32 \mu \mathrm{m}$. Similarly the mass concentration in the next larger size-class, that of $0.32-0.56 \mu \mathrm{m}$, is given by the vertical difference between the next two lines.

\subsection{Sulphate}

For sulphate the evaluation was more complex than for nitrate. Quite disturbing were episodes, lasting for some of hours, with extremely high concentrations of sulphur dioxide and associated high concentrations of total aerosol sulphate. The high concentrations were suspect, because they were not registered by the sulphur dioxide monitor of the national network, sited at the same location. We therefore first analysed the data in these periods. It was found that the drain from the gas-denuder contained only sulphate, while in all other instances sulphite was the dominating sulphur-form in which the sulphur dioxide was taken up. It was therefore inferred that the signal did not derive from the uptake of sulphur dioxide but from deposited sulphate, most likely coarse gypsum grains used in the paint-job performed at the tower at the time.

There was a concern that the large amounts of coarse sulphate would interfere with the measurement of the submicron size-distribution, either directly or by carry-over of analyte in the aqueous analysis train. It turned out, in the contrary, that the interference could be used to its advantage in quantifying the carry-over, in the following sense. After analysis of the drain from the denuder the next step in the analysis cycle is that of the totalaerosol line. The concentration in this line was $2 \%$. This can derive from carry-over of denuder analyte.

The actual carry-over is less than the value given, because there is real aerosol sulphate in the total sulphate line. A lower estimate is obtained from measurement of the sulphate in the next step in the cycle. This is the submicron sulphate. The signal in this channel is about half of that in the total sulphate line. In turn, the same amount/concentration of submicron sulphate must be present in the total sulphate line. Hence this amount can be subtracted from the total sulphate. This would mean that carry-over amounts to $1 \%$. Such a small value is an insignificant interference, as can be seen in Fig. 3 from the differences in concentration in consecutive steps.

A second issue with the evaluation of the sulphate data is the performance of the denuder in case of (partial) drying-up. While a dry denuder is still fully efficient in removing nitric acid and hydrochloric acid, it is questionable whether it would remove the less reactive sulphur dioxide and ammonia. It is obvious that, when these gases are not removed in the denuder, they are sampled by the aerosol collector and thus counted as aerosol ingredient.

It could be established that the denuder was fully effective in the dry state for sulphur dioxide from a close examination of the blanks. The blank is obtained via the line with the aerosol-filter through which only the gases pass. It appeared that the blanks in periods with a dry denuder were as low as 
in the periods that the denuder was wet. There is also other evidence.

The site in Cabauw houses, as discussed, a sulphur dioxide monitor. On days on which concentrations of the gas as measured with this instrument were as high as $12 \mu \mathrm{g} \mathrm{m}^{-3}$, the blank value in the MARGA-sizer was close to the standard blank value of $0.33 \mu \mathrm{g} \mathrm{m}^{-3}$. This shows that a dried denuder does not lose its efficiency in the removal of sulphur dioxide. Moreover, in assessing the concentrations of the size-classified sulphate the blank is subtracted and this value did not have a systematic difference between measuring cycles. The LOD for sulphate, though, was higher than that for nitrate, with a value of $0.31 \mu \mathrm{g} \mathrm{m}^{-3}$.

A summary of the results obtained with the monitoring of sulphate is as follows: the concentration of total sulphate was $2.0 \mu \mathrm{g} \mathrm{m}^{-3}$. This value is corrected for the blank and with omission of the mentioned outliers. The average concentration of the submicron fraction was not significantly different from that of total sulphate. (Incidentally, the average concentration of submicron nitrate was also $2.0 \mu \mathrm{g} \mathrm{m}^{-3}$.)

$55 \%$ of the sulphate was in particles smaller than $0.32 \mu \mathrm{m}$ in diameter. $26 \%$ of the sulphate resides in the smallest particle fraction, i.e., particles with a diameter smaller than $0.18 \mu \mathrm{m}$.

\subsection{Ammonium}

Evaluation of the data for ammonium was the most complex. The reason is that the method for analysis of this component depends on temperature and that the zero setting therefore also varies with temperature. A zero off-set as such is not a problem, because it is part of the blank. This blank is measured during every measuring cycle and then subtracted. However, as mentioned, the instrument was exposed to quite extreme temperatures and in this episode the difference in the blank in consecutive cycles was high relative to the concentrations and it was not certain what its value was in the measuring period in-between. Therefore the data obtained in the particular week with the extreme temperatures were not considered. In the rest of the time the LOD for ammonium was similar to that for sulphate.

The denuder also appeared to operate well in removing ammonia in case of incomplete wetting. This could be deduced from the very low blank values. These were even low in episodes of high ammonia concentrations as reported by the national network (http://www.lml.rivm.nl/data/index.html).

\subsection{Ion balance}

The ion balance between ammonium and nitrate/ sulphate has a rather large uncertainty because of the accumulated uncertainty in the individual concentrations, specifically that of ammonium. This is the situation for a single measuring cycle. We therefore evaluated the average ion balance over periods of a week and found that it was close to unity. The uncertainty is rather large because of a substantial number of data near or below the LOD, especially for ammonium. The Standard Deviation from the mean was 0.16 . The uncertainty in the ion balance for the size-fractions is proportionally higher.

Chloride was measured in view of its possible role in the ion balance. Its lower detection limit of $0.03 \mu \mathrm{g} \mathrm{m}^{-3}$ was the best of all components measured. It was only because of this low value that the concentration in the submicron range could be assessed. With a value of $0.11 \mu \mathrm{g} \mathrm{m}^{-3}$ it is smaller than the combined uncertainty in the concentrations of the other components. Chloride is therefore not significant in the ion balance. Incidentally, the low value for submicron chloride is in line with a similar low average value found earlier by Chang et al. (2001) with manual sampling.

\section{General discussion}

\subsection{General observations}

We developed a new instrument to semi-continuously monitor the concentration and size-distribution of nitrate, sulphate, ammonium and nitrate. The instrument was successfully deployed in a measuring campaign of two months at the meteotower of Cabauw in the centre of the Netherlands. The apparatus apparently worked well, as evidenced by the good comparability of the concentration of total nitrate, aggregated over $24 \mathrm{~h}$, with the daily value interpolated from data of the dense national network. In this network nitrate is measured with representative means (Schaap et al., 2004). Good comparability was also observed for the other major anion, sulphate.

The number of measuring days may seem limited, however it should be appreciated that the total number of data is over four hundred; for cost 
reasons a similar number of manual measurements would not have been feasible with classical cascadeimpactor sampling. Even more importantly, representative data on the size-distribution for the semivolatile (ammonium) nitrate were obtained.

While $80 \%$ of the nitrate is in aerosols smaller than $1 \mu \mathrm{m}$ in diameter, there was also some hypermicron nitrate. This is in contrast to sulphate that only occurred in the submicron particles. The concentrations of sulphate and nitrate in the submicron range were quite similar. On average $46 \%$ of the submicron nitrate was in particles smaller than $0.32 \mu \mathrm{m}$, which is only marginally different from the value for sulphate $(53 \%)$. Sulphate was more concentrated in the smallest particles, those smaller than $0.18 \mu \mathrm{m}$, than nitrate. This implies as discussed in the introduction, that the light-scattering associated with sulphate was less than that by nitrate.

\subsection{Diurnal variation}

With respect to the diurnal cycle it had been expected that the semi-volatile (ammonium) nitrate would exhibit a maximum at night and a minimum at daytime in the summer. In contrast, in some periods during the campaign the daytime values were significantly higher (e.g., Fig. 3). However over the campaign as a whole a systematic difference between day and night was not observed. Incidentally a daytime maximum was also observed in the measurements of Stolzenburg et al. (2003) in California. Such behaviour seems to be a very interesting case for further analysis.

The size-distribution of either nitrate or sulphate did not show a systematic diurnal change. A difference was expected, because of a difference in the formation routes between night and day. At night the compounds are produced via heterogeneous reactions at or in existing aerosol, while at day they are formed via photochemical pathways in the gas-phase with subsequent transfer to the particulate phase. This could imply that there is a difference in the resulting size-distribution of the components over a daily cycle. However, the data do not contain evidence for such a diurnal cycle in the size-distribution and hence do not provide support for a specific formation route.

We realise that the data set is rather limited and obtained with research-type instrumentation and that longer term-monitoring is required, also in other seasons, to obtain more insight in the diurnal cycling of the compounds in question. This is the approach followed at present in a new study in which second generation instrumentation is being developed that features improved sensitivity using a sampling column, and the addition of a cationdetector for ammonium.

\subsubsection{Addendum}

Prior to the actual monitoring campaign a testrun of a week was made in spring. The average concentration of submicron nitrate was much higher than that in the summer campaign (compare Figs. 2 and 4). Half of the mass of nitrate (Fig. 4) was contained in particles smaller than $0.32 \mu \mathrm{m}$ in diameter. This is similar to the situation in the summer campaign and an indication that the sizedistribution of ammonium nitrate is not a sensitive function of the atmospheric loading.

\section{Conclusions}

We developed a technique for measuring the sizedistribution of the major ionic species in submicron aerosol with a time-resolution of $2 \mathrm{~h}$. With this instrument the first unbiased data on the sizedistribution of (ammonium) nitrate in summer in the Netherlands were obtained.

The data, a total of over four hundred gathered over a period of two months, showed that the
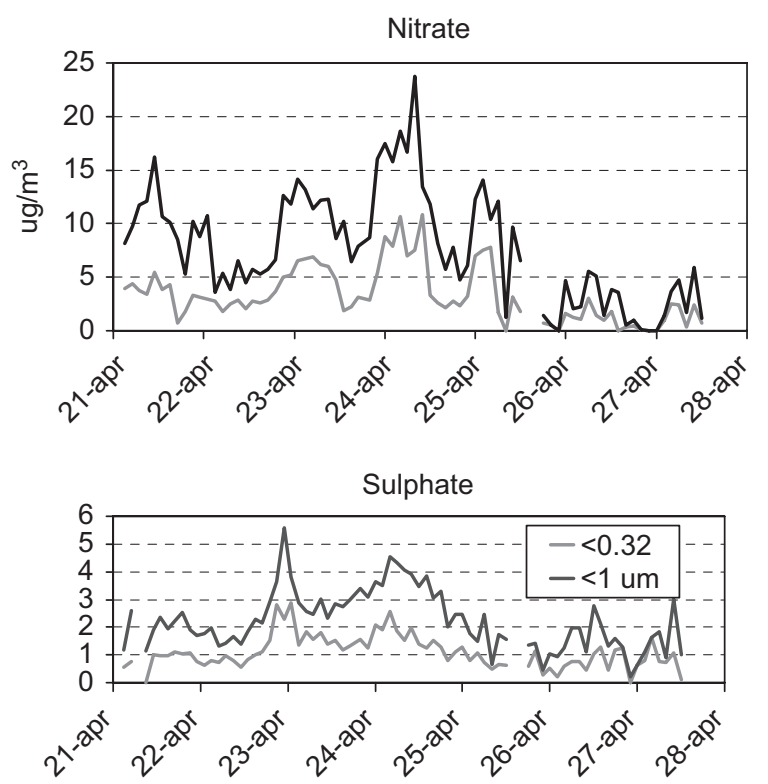

Fig. 4. The concentration of submicron nitrate and sulphate in a test-week in spring at the same location as described in Fig. 2. Notice the different scales for the two components. 
ammonium nitrate is for the most part in the submicron range, with $46 \%$ of the mass in particles smaller than $0.32 \mu \mathrm{m}$. The ratio of submicron nitrate to sulphate was very close to unity. In a short test in spring, with highly elevated concentrations of nitrate, a similar mass-distribution as a function of size was found.

While the concentrations of submicron nitrate and sulphate were the same in the campaign, it was inferred that the light-scattering by sulphate was less than that by nitrate, because a larger part of the sulphate resided in particles that are too small to effectively scatter light.

Contrary to expectations, daytime maxima for nitrate occurred.

There was little diurnal variation in the sizedistribution of nitrate and sulphate.

A longer data set is required to generalise the current findings.

\section{Acknowledgements}

We are grateful for the support by the ministry of Housing, Spatial Planning and The Environment (VROM) of the Netherlands. Part of the analysis of the data was performed within the EU-project CREATE (EVK2 - CT 2002-00173). We gratefully acknowledge the use of classified data from the National Network on Air Quality (LML) of RIVM. We are greatly indebted to an anonymous reviewer for the many valuable remarks and suggestions.

\section{References}

Adams, P.J., Seinfeld, J.H., Koch, D.M., Mickley, L., Jacob, D., 2001. General circulation model assessment of direct radiative forcing by the sulfate-nitrate-ammonium-water inorganic aerosol system. Journal of Geophysical Research 102 (D1), 1097-1111.

Allen, A.G., Harrison, R.M., Erisman, J.W., 1989. Field measurements of the dissociation of ammonium nitrate and ammonium chloride aerosols. Atmospheric Environment, 1591-1599.

Chang, M.C., Sioutas, C., Fokkens, P.H.B., Cassee, F.R., 2001. Development and field evaluation of a high-capacity particle size classifier (HCPSC) for separate coarse, fine and ultrafine particle collection. Journal of Aerosol Science 32, 139-156.

Dougle, P.G., Veefkind, J.P., ten Brink, H.M., 1998. Crystallisation of mixtures of ammonium nitrate, ammonium sulfate and soot. Journal of Aerosol Science 29, 375-386.

Fine, P.M., Jaques, P.A., Hering, S.V., Sioutas, C., 2003. Performance evaluation and use of a continuous monitor for measuring size-fractionated $\mathrm{PM}_{2.5}$ nitrate. Aerosol Science and Technology 37, 342-354.
Finlayson-Pitts, B.J., Pitts, J.N., 2000. Chemistry of the upper and lower atmosphere. Academic Press.

Jacobson, M.Z., 2001. Global direct radiative forcing due to multicomponent anthropogenic and natural aerosols. Journal of Geophysical Research 196, 1551-1568.

Khlystov, A., Even, A., ten Brink, H.M., 1997. Effect of temperature, ammonia concentration and flow rate on under-sizing of ammonium nitrate aerosol in DMPS/SMPS. Journal of Aerosol Science 28, S59-S60.

Marple, V.A., Rubow, K.L., Behm, S.M., 1991. A microorifice uniform deposit impactor (MOUDI): description, calibration and use. Aerosol Science and Technology 14, 434-446.

Mikuska, P., Even, A., Khlystov, A., ten Brink, H.M., Slanina, J., 2001. Artifact-free method for size-resolved chemical analysis of ambient aerosols. Journal of Aerosol Science 28, S443-S444.

Nemesure, S., Wagener, R., Schwartz, S.E., 1995. Direct shortwave forcing of climate by anthropogenic sulfate aerosol: sensitivity to particle size, composition, and relative humidity. Journal of Geophysical Research 100, 26105-26116.

Penner, J.E., Andreae, M., Annegarn, H., Barrie, L., Feichter, J., Hegg, D., Jayaraman, A., Leaitch, R., Murphy, D., Nganga, J., Pitari, G., 2001. Aerosols, their Direct and Indirect Effects; Chapter 5 in Climate Change 2001: the Scientific Basis. Cambridge University Press.

Putaud, J.-P., Raes, F., Van Dingenen, R., Brüggemann, E., Facchini, M.C., Decesari, S., Fuzzi, S., Gehrig, R., Huglin, C., Laj, P., Lorbeer, G., Maenhaut, W., Mihalopoulos, N., Müller, K., Querol, X., Rodriguez, S., Schneider, J., Spindler, G., ten Brink, H.M., Tørseth, K., Wiedensohler, A., 2004. A European aerosol phenomenology-2: chemical characteristics of particulate matter at kerbside, urban, rural and background sites in Europe. Atmospheric Environment 38, 2579-2595.

Robles Gonzalez, C., Schaap, M., de Leeuw, G., Builtjes, P.J.H., van Loon, M., 2003. Spatial variation of aerosol properties over Europe derived from satellite observations and comparison with model calculations. Atmospheric Chemistry and Physics 3, 521-533.

Schaap, M., Spindler, G., Schulz, M., Acker, K., Maenhaut, W., Berner, A., Wieprecht, W., Streit, N., Müller, K., Brüggemann, E., Chi, X., Putaud, J.-P., Hitzenberger, R., Puxbaum, H., Baltensperger, U., ten Brink, H.M., 2004. Artefacts in the sampling of nitrate studied in the "INTERCOMP" campaigns of EUROTRAC-AEROSOL. Atmospheric Environment 38, 6487-6496.

Seinfeld, J.H., Pandis, S.N., 1998. Atmospheric Chemistry and Physics: From Air Pollution to Climate Change. Wiley, New York, USA.

Slanina, J., ten Brink, H.M., Otjes, R.P., Even, A., Jongejan, P., Khlystov, A., Waijers-IJpelaan, A., Hu, M., Lu, Y., 2001. Continuous analysis of nitrate and ammonium in aerosols by the Steam Jet Aerosol Collector (SJAC): extension and validation of the methodology. Atmospheric Environment 35, 2319-2330.

Stolzenburg, M.R., Dutcher, D.D., Kirby, B.W., Hering, S.V., 2003. Automated measurement of the size and concentration of airborne particulate nitrate. Aerosol Science and Technology 37, 537-546.

ten Brink, H.M., Veefkind, J.P., Waijers, A., van der Hage, J.C., 1996. Aerosol light-scattering in The Netherlands. Atmospheric Environment 30, 4251-4261. 
ten Brink, H.M., Kruisz, C., Kos, G.P.A., Berner, A., 1997. Size/ composition of the light-scattering aerosol in the Netherlands. Atmospheric Environment 31, 3955-3962.

Trebs, I., Meixner, F.X., Slanina, J., Otjes, R., Jongejan, P., Andreae, M.O., 2004. Real-time measurements of ammonia, acidic trace gases and water-soluble inorganic aerosol species at a rural site in the Amazon Basin. Atmospheric Chemistry and Physics 4, 967-987.

Veefkind, J.P., 1999. Aerosol satellite remote sensing. Ph.D. Thesis, University of Utrecht. 